\title{
Construction of the Tutor Team in Postgraduate Education
}

\author{
Huang Deling \\ College of Software Engineering, Chonqing University \\ of Posts and Telecommunication \\ Chongqing, China \\ huangdl@cqupt.edu.cn
}

\author{
Xia Shufang \\ College of Software Engineering, Chonqing University \\ of Posts and Telecommunication \\ Chongqing, China \\ xiasf@cqupt.edu.cn
}

\begin{abstract}
The training quality of postgraduate students has always been a focus in the education industry. Proper ratio of tutor and students is the precondition for it. The existing tutor mode cannot afford the enrollment expansion. Tutor team is desired, which can eliminate the conflict between enrollment expansion of postgraduates and lack of tutors. A well configured tutor team can also improve the quality of both the students and the tutors. Scientific research resources and knowledge are well shared under tutor team mode. The constructing mode is proposed, including the team composing mode, tutoring pattern, team management rules and the quality monitoring system.
\end{abstract}

Keywords-tutor team; postgraduate; quality monitoring system; chief tutor; external tutor

\section{INTRODUCTION}

China is facing a fast shifting to scientific and technological innovation and progress. Well educated people have become the most important part of the work force which push the economic development and construct an innovative country [1]. Postgraduate is the main part of this highly educated group. The training quality of postgraduate students has always been the focus during training highly educated group. However, the training quality of postgraduates has shown a worrying status under the single tutor system these years.

The postgraduate education of China has encountered a rapid development. The number of enroll new students has greatly increased year by year. The enroll number was 608 thousand in 2013 while it was 260 thousand in 2003 [2]. However, the tutors of postgraduates are not experiencing such overwhelming increase. Relevant researches indicate that $15.7 \%$ of the tutors are guiding synchronously more than 10 postgraduates. And the number comes to be more than 20 or even 30 for some $1 \%$ of the tutors. We all know that everyone's energy is limited. There won't be sufficient guidance for each postgraduate if a tutor is guiding simultaneously too many students. Second, if there is no backup, all students of a tutor will be with no guiding if their tutor is on a business trip or absent for some other reasons. Furthermore, there are more and more interdisciplines nowadays, but one tutor is always professional at a special area [3]. These are a pair of contradictories. If there are some others to support the unfamiliar area for a single tutor, it would be a remedy for the boundedness of a single tutor.

Generally, the capability of postgraduate student is largely affected by his or her tutor's ability [4]. A good tutor can stand in the forefront of an area and can foresee the developing direction of the research area. Meanwhile, the tutor inspires and affects students though teaching, scientific research and ideological education. And they guide the students using their own innovative consciousness with their own innovative ability [5]. So the students' research activities are to some extent limited to a certain tutor's capability. Hence, it is necessary to construct tutor teams [6]. Tutors in a team can make their respective advantages complementary to each other. Consequently, students will benefit more from their tutors.

\section{Advantages of TUtOR TeAm}

\section{A. Improve the teachers' quality}

Tutors within a team will improve their own research capability during the communication with other tutors from different areas, different majors or even different disciplines. They enlarge and renew their knowledge, broaden their research thought, stimulate their research inspiration, boost the thinking activity, and then promote their own research level [7]. Veteran teachers have rich experiments. They can set good examples to the other tutor, and are beneficial to form a good academic environment for everyone in the team. Younger teachers have active thinking, who will find pleasure in accepting new things. They are willing to try kinds of new ideas, and to adopt new research method. Thus, the veteran tutors and the younger tutors can make mutual supplement and improvement. And, younger tutors can promptly improve their capability to guide a postgraduate during cooperating and communicating with the veteran teachers. Through these activities, a well-structured postgraduate tutor team is born, which has higher academic level than any single one in the team.

\section{B. Improve the postgraduates' quality}

Tutors within a team may be with different majors, come from different faculties in the university, or even come from different universities or research organizations or enterprises [8]. They are with different specialties, educational backgrounds and scientific insights. Postgraduate students may cost one or more than one year to find out their interesting point, during which they communicate with different tutors. This process gives students widely enough sight, rather than restricts them to a single tutor's research area. After that, they can receive totally different suggestions on different problems or even on the same problem. This also enlarges their thinking and trains their decision-making capability. On the other hand, students will gain from more than one tutor their respective 
advantages, from more than one university their respective superiorities.

\section{Bring up new ideas}

Discussing with tutors from different disciplines helps to yield innovational ideas. Traditional scientific research, including reading literature, performing experiments, and discussing problems and etc, are always restricted to a certain area. It comes to a result that, researches are difficult to get breakthrough progress. On the contrary, if other methods or concepts from other disciplines can be introduced into, new ideas with brand new innovation will always come into being. Besides, the questions from other discipline can trigger further thinking of the researchers from multiple angles. This is why the developing trend of interdisciplinary area is so popular. Tutor team provides an ideal environment for inter-discipline. Tutors make professional guide for the students from different respects, and the students can integrate the research ideas and make the mind mode clearer, with hardly any risk of off-track.

\section{Make good use of the research resource}

Tutors within a team can share their research resources, including experimental equipments, interpersonal relationships, and other research infrastructures. It can avoid repeated cost of kinds of hardware and software. Sharing within the team not only the knowledge but also the equipments makes a good use of the scientific research funds. This benefits not only the university, but also the country and the whole world.

\section{CONSTRUCTING TUTOR TEAm Mode}

Tutor team requires several tutors work together as a team and carry out a united guidance to a postgraduate student. This kind of tutor mechanism originated from doctoral candidates' education in U.S.A. It is widely adopted in the burgeoning inter-disciplines for training academic type of postgraduate students, as it is beneficial to promote different disciplines' crossing. And because of the current situation mentioned in section 1, it is necessary implementing tutor team system for postgraduate education in China. We here propose some rules on the way of constructing tutor team mode.

\section{A. Team composing mode}

When selecting tutors for a team, we should take into account the major, the age, the sex and etc. It is better that the tutors within a team are of different specialties, majors, disciplines, titles and knowledge levels. They can form an echelon, where senior teachers can set an example to young teachers, and thus the echelon will keep a sustainable development. Furthermore, they must open their lab infrastructures, scientific research projects and experimental equipments to all the postgraduate students of their team.

A feasible configuration of the tutor team is: one internal chief tutor, one external tutor, several assistant tutors. Only senior teacher can be selected as chief tutor, who is in charge of postgraduates' education schemes, and monitor the implementation of it. The external tutor comes from large enterprises or scientific research institutes or hitech private companies, better with senior professional titles. The assistant tutors should have masters' degree or above and with middle titles. The tutor team is established during the postgraduate choosing his or her research subject on the third semester. Before this, every tutor in the team has the responsibility to guide the students in the team. The tutor team for a postgraduate is established through a coordination platform, from which the division of all tutors' rights, the liability and interest of each tutor can be achieved.

There must be a principal in charge of the whole tutor team. He determines every tutor's duty, and is responsible for the working schedule. Tutors in the team report to the principal, while the principal reports to the university. The tutor model of our proposed tutor team mode is shown in Fig.1.

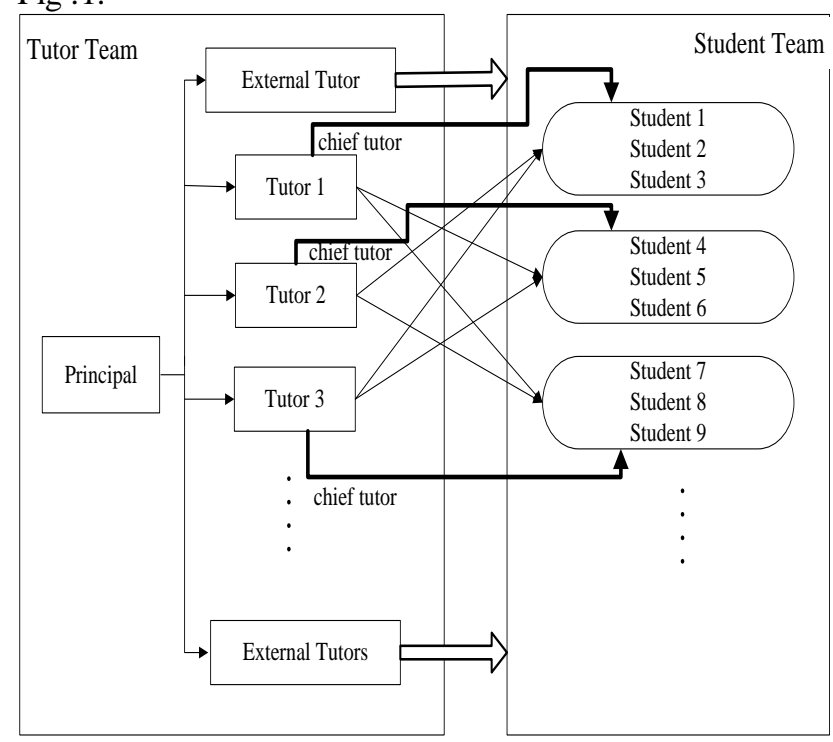

Figure 1. Team composing mode

The tutor team presents as a unit when enrolling new postgraduate students. Students no longer have to choose a certain tutor when applying for a university, which sometimes results in that they missing their wish and are allocated to an unexpected major or university. With tutor team, students only have to pay attention to the field they are interested in before they take the entrance examination. They can determine their tutors after having stepped into the campus and when having understood more about the field. During the training, the tutor can even be changed inside the team as is needed in some special situation. Therefore, the postgraduate training becomes more flexible and more reasonable.

\section{B. Tutor Pattern}

Tutors are not allocated to students who haven't finished their course. All tutors in the team have to announce at least a time slot per week, during which they must stay in their office and be available for all the students in the team. When choosing the research subjects, postgraduate are assigned a chief tutor, who helps his students grasping their research direction. Students are also assigned several assistant tutors, who help them adapting to diversification knowledge in different majors and different disciplines. One external tutor is assigned to a student to help him or her in keeping researching subject be with practical value, and keeping pace with the theory and method widely used in practical. 
"Apprenticeship Education" of German University and "Smoke-spraying Mode" of University of Oxford and University of Cambridge [9] are introduced. Periodical seminar between the tutor teams and postgraduates should be held every one or two weeks. All tutors in the team must take part in the seminar, including the external tutors. A good coordinate mechanism is required to get this huge team get together four or two times a month. It must be supported both by the university and the enterprise, rather than a personal behavior. As these people, tutors and postgraduate students, get together, discussions are carry out among different disciplines with different research understandings. Questions are raising, diverse solutions are offered, and knowledge is sharing... Moreover, this kind of communications can breadthough the boundedness born with a certain discipline. They play an important part in innovation. They can help to collect brand new research ideas, and to make the researchers' mind clearer. Besides, they can train participants the capability of argumentation, logic thinking and innovative thinking.

Another important part of improving training quality of postgraduate student lies in integrating theory and practice. Calling in external tutors in the tutor team is an effective method of making the theory students have learnt keep pace with the practice. Besides, we can make good use of the social network of the tutors in the team. They can introduce students in the team to some practice sites. The sites could be an administration department of the university, or an enterprise, an organization outside the campus and etc. Tutors are with different backgrounds, so the practice sites are various, and would be more than a single tutor can contact, or than the students themselves can search out. Besides, the sites discovered by the students may not be secure enough. Moreover, searching for these sites themselves may costs a lot of the energy of postgraduate students. Sites collaborate with the tutor team will eliminate all these issues. Through practice, students accelerate their combining theory with practice, enlarge their academic view, promote their emergency-dealing capability, and obviously improve their comprehensive quality.

In order to carry out effective classroom learning, tutor team should contribute to the courses of the postgraduate students. They can teach lessons, make them complete and make appropriate innovation. The tutor team should also cooperate in guiding students writing dissertation, choosing researching subject, mid-term inspection and thesis defense. All these steps should be supervised under the tutor team. Consequently, the research subject and its feasibility, the research schedule and achievement of every phase, and the final thesis are all under the same examine and verify. This teamwork makes a standard flow of postgraduate training, and provides more standard and fairer training.

\section{Team Management Rules}

A series of management rules can guarantee tutor team mechanism work effectively. The relationships among the tutor team members are relatively complicated. Tutors within a team may come from different majors, different faculties, or even different universities. Some of them may have different jobs, and belong to different tutor teams.
Buck-passing responsibility in the tutor team may always happen if there is no well-run management.

First, every tutor should have a specific duty. The principal formulates the training scheme of the team, coordinates configuration and usage of all the research resources, guides and monitors team members carrying out the training scheme, and directs the team. He should also harmonize the relationships among all the members in the team, and stimulate every tutor's enthusiasm and creativity. Every member of the tutor team should follow the training scheme, and tutor the students in the team. Each tutor should cover the minimum required tutoring time, and avoid impacting tutor due to other missions.

Second, academic divergences between tutors should get well settled. Every tutor has his or her own academic concept and his or her own way of thinking. Everybody has equal academic right, no matter what title he or she has. Thus everyone, no matter the principal or the young tutor, has the equal right to speak when solving academic problems. Everyone should agree to disagree, and respect others' different opinions. Each tutor, especially the senior teacher should avoid ending academic argues though administrative approaches.

\section{Monitor system for training quality}

Constructing monitor system for postgraduate training quality is an effective guarantee for the postgraduate training quality [10]. The existing monitor systems are based on single tutor. The management mainly lies on the faculty and in distributed mode. In tutor team system, teams are crossing faculties and colleges, the monitor system should be centralized to the university. Tutors in the team report to the principal of the team, while the principal reports to the university. The system should mainly include management system, evaluation system and information feedback system. Tutor team is a new concept. There may be some issues when practicing it. With monitor system, we make in-time correction, and thus guarantee the training quality. When the quality of postgraduate students shows a large improvement under tutor team mode, it will widely adopted by the society. So constructing monitor system for postgraduate training quality based on tutor team is important for the generalization of tutor team system.

\section{CONCLUSION}

The proposed tutor team mode for postgraduate education in this paper leads to interaction between the tutor teams and the postgraduates on a quality monitor system. We have practice this mode in our laboratory, and have gained much from it. Hope the mode will benefit more organization training postgraduate students.

\section{ACKNOWLEDGMENT}

This research was financially supported by Program for Innovation Team Building at Institutions of Higher Education in Chongqing (Grant No. KJTD201310), Program for Postgraduate Education and Teaching Reform in Chongqing (NO.yjs 131008, NO. yjs153028).

\section{REFERENCES}

[1] Yan-Bo N I, Zhang Y X, Zhang L X, et al. "Exploration on Constructing Postgraduates Training Mode with Team Supervisor System," Value Engineering, 2014. 
[2] Ye F, Xu M, Peng H. "Evaluation on tutor team training mode in training of emergency post trainee," Chinese General Practice Nursing, 2015.

[3] Chen H, Hou C, Fan L, et al. "Tutor Group Co-culture Mode to Upgrade the Postgraduate Innovative Ability," Higher Education in Chemical Engineering, 2015.

[4] Ya-Lin L I, Zhou C Y. "Strengthening Graduates Tutor Teams Construction to Guarantee Quality of Postgraduate Education," Pharmaceutical Education, 2012.

[5] Chen H, Hou C, Fan L, et al. "Tutor Group Co-culture Mode to Upgrade the Postgraduate Innovative Ability," Higher Education in Chemical Engineering, 2015.

[6] Qu H, Wang W, Jian S. "Reflections and Exploration on the Reform of Cultivation Model for Information Postgraduates," Science Education Article Collects, 2014.
[7] Ran X U, University L. "On Science and Engineering Graduate Students' Tutor Team Building," Guide of Science \& Education, 2014.

[8] Miao Y, Xiao T, He J, et al. "Research Into Construction Mode Of Postgraduate Tutor Teams Based On Knowledge Management," Management and Service Science (MASS), 2010 International Conference on. 2010:1-3.

[9] Luo N S, Zhao H P, Wen-Ping W U. "Studying on Supervisor Team Construction and Postgraduate Cultivation Quality in Western Underdeveloped Area-A Case Study of Jishou University," Jornal of Jho Nvry Oal N Don, 2012.

[10] Dunworth H S S K. "Issues and agency: postgraduate student and tutor experiences with written feedback," Assessment \& Evaluation in Higher Education, 2014, 40(3):1-15. 